\title{
Evidence for Natural Selection in the Mitochondrial Genome of Mycosphaerella graminicola
}

\author{
J. Zhan, G. H. J. Kema, and B. A. McDonald
}

First and third authors: Institute of Plant Sciences, Phytopathology Group, ETH Zentrum/LFW, Universitätstrasse 2, CH-8092 Zürich, Switzerland; and second author: Plant Research International, B.V. P.O. Box 16, 6700 AA Wageningen, The Netherlands. Accepted for publication 9 December 2003.

\begin{abstract}
Zhan, J., Kema, G. H. J., and McDonald, B. A. 2004. Evidence for natural selection in the mitochondrial genome of Mycosphaerella graminicola. Phytopathology 94:261-267.

Pathogenicity assays were combined with restriction fragment length polymorphism (RFLP) markers in the mitochondrial and nuclear genomes to compare Mycosphaerella graminicola populations adapted to bread wheat (Triticum aestivum) and durum wheat (T. turgidum) in the Mediterranean Basin. The majority of isolates had unique nuclear DNA fingerprints and multilocus haplotypes. Only six mitochondrial DNA (mtDNA) haplotypes were identified among 108 isolates assayed. There were minor

differences in frequencies of alleles at nuclear RFLP loci between the two host-adapted populations, but differences in the frequencies of mtDNA haplotypes were highly significant $(P<0.0001)$. mtDNA haplotype 1 dominated on the isolates adapted to bread wheat, and its frequency was twice as high as for the isolates adapted to durum wheat. mtDNA haplotype 4 , which contained a unique $\approx 3-\mathrm{kb}$ insertion, was detected only in isolates showing specificity toward durum wheat and was the dominant haplotype on this species. We propose that the low mitochondrial diversity in this pathogenic fungus is due to a selective sweep and that differences in the frequencies of mtDNA haplotypes between the two host-adapted populations were due to natural selection according to host species.
\end{abstract}

Natural selection may increase or decrease the level of genetic variation and population differentiation in a species, depending on the type of selection operating (23). Directional selection for the same ecological and physiological characters in populations inhabiting different environments may lead to a rapid decrease in genetic variation of a species and homogenize the genetic structure of geographic populations in a process called a selective sweep $(19,54)$. On the other hand, divergent selection for different ecological and physiological characters among genetically isolated populations may lead to population subdivision (42). Speciation ultimately results when reproductive isolation occurs as a result of accumulation of differences among populations existing in various ecological niches (ecological selection) or due to exploitation of alternative host resources (host specialization [46]). In pathogens undergoing sympatric speciation, host specialization plays an important role in the formation of reproductive isolation. Adaptation of pathogens to specific host genotypes could lead to positive assortative mating, which limits exchange of genetic information among pathogen populations.

In agricultural ecosystems, natural selection and host specialization are major evolutionary forces affecting the genetic structure of pathogen populations (34). These forces are responsible for the erosion and breakdown of resistance genes and the loss in effectiveness of fungicides or antibiotics. In gene-for-gene systems of pathogen-plant interaction, plant resistance genes encode receptors that (directly or indirectly) recognize elicitors encoded by avirulence genes in corresponding pathotypes of the pathogen population (51). Evolution in the pathogen population begins with a mutation that causes the elicitor to evade recognition by the host receptor. Individuals with this mutation become virulent, cause

Corresponding author: J. Zhan; E-mail address: jiasui.zhan@ipw.agrl.ethz.ch

Publication no. P-2004-0115-01R

(c) 2004 The American Phytopathological Society disease on the previously resistant host, and increase in frequency on the associated host as a result of natural selection. In plant pathosystems lacking gene-for-gene interactions, natural selection can also increase the overall aggressiveness of pathogen populations, leading to a gradual erosion of quantitative resistance (37).

Since the early 1970s, mitochondrial genomes have been widely used to study the evolutionary biology of species (31). Compared with its nuclear counterpart, the mitochondrial genome offers many advantages to address evolutionary questions, especially those connected to natural selection (10). In many mammals and plants, mitochondrial genomes evolve faster than nuclear genomes (47). Mitochondrial genomes usually exhibit uniparental inheritance $(7,47)$, which does not involve meiosis. Even for species with biparental inheritance, recombination between maternal and paternal types of mitochondria appears to be extremely rare (7, but see 49). The nonrecombining mode of inheritance often provides multiple alleles or haplotypes that can be interpreted as gene genealogies (4), because all alleles at a locus are thought to originate from the same ancestor with differences accumulating only through mutation. Furthermore, it was demonstrated previously that mitochondrial genomes are not selectively neutral $(5,43)$ and that mitochondrial haplotypes within many species can be arrayed according to geographical origin (3).

Mycosphaerella graminicola (Fückel) Schroeter (anamorph Septoria tritici) is the causal agent of Septoria tritici leaf blotch on wheat and other graminaceous hosts (9). The pathogen has a global distribution and causes significant yield losses in many areas of the world (17). Population genetic and epidemiological studies with molecular markers and morphological characters revealed that the fungus is characterized by a high degree of genetic variation in the nuclear genome $(38,40)$, high levels of gene flow (63), repeating cycles of sexual recombination $(12,24,29,61)$, and large effective population size (62), suggesting a high evolutionary potential (37).

Host specialization in $M$. graminicola has been considered for 30 years $(1,18,26,27,36,53,60)$, but the results have been incon- 
sistent. Van Ginkel and Scharen (53) did not find significant hostpathogen interactions in the wheat- $M$. graminicola pathosystem. They found that isolates of $M$. graminicola varied for aggressiveness rather than virulence and concluded that clear gene-for-gene interactions were absent in this plant pathosystem. Other studies indicated a significant degree of specificity, suggesting that a gene-for-gene interaction exists between host and pathogen (18, 26,27). Since avirulence in $M$. graminicola can be controlled by a single locus (30) and many wheat cultivars can carry single genes for resistance $(8,17,36)$, it is now shown that gene-for-gene interactions between wheat and $M$. graminicola do exist $(8,30)$. However, results based on changes in the frequencies of marked genotypes on cultivars differing in resistance indicated that host specificity could be complex in the wheat $-M$. graminicola pathosystem (60). Isolates originating from the same field varied in their degree of host specialization, ranging from being very host cultivar specific to generally host cultivar nonspecific, illustrating that the wheat $-M$. graminicola pathosystem is characterized by quantitative as well as qualitative aspects of pathogenicity (27, 28). In contrast, all investigations that included fungal isolates sampled from durum wheat as well as bread wheat discovered significant levels of host species specificity $(26,27)$.

The objective of this study was to determine whether natural selection is responsible for the low genetic variation observed in the mitochondrial genome of $M$. graminicola.

TABLE 1. Adaptation of Mycosphaerella graminicola isolates to bread wheat or durum wheat ${ }^{\mathrm{a}}$

\begin{tabular}{|c|c|c|c|c|}
\hline \multirow[b]{2}{*}{ Country } & \multirow[b]{2}{*}{ Location } & \multicolumn{3}{|c|}{ Number of isolates adapted to } \\
\hline & & $\begin{array}{l}\text { Bread } \\
\text { wheat }\end{array}$ & $\begin{array}{l}\text { Durum } \\
\text { wheat }\end{array}$ & Both \\
\hline \multirow[t]{15}{*}{ Algeria } & Ain Berda & 1 & $\ldots$ & $\ldots$ \\
\hline & Azzaba & 1 & 1 & $\ldots$ \\
\hline & Berrahal & 12 & 14 & 2 \\
\hline & Bouchegouf & $\ldots$ & 1 & $\ldots$ \\
\hline & Drean & $\ldots$ & 1 & $\ldots$ \\
\hline & Elkarma & $\ldots$ & 1 & $\ldots$ \\
\hline & Gmelig & 1 & $\ldots$ & $\ldots$ \\
\hline & Guelma & 6 & 1 & $\ldots$ \\
\hline & Hazer & $\ldots$ & 1 & $\ldots$ \\
\hline & Khroub & $\ldots$ & 1 & $\ldots$ \\
\hline & Menzel el abtal & $\ldots$ & 4 & $\ldots$ \\
\hline & Oum Bouachi & $\ldots$ & 1 & $\ldots$ \\
\hline & Rahouia & $\ldots$ & 2 & $\ldots$ \\
\hline & Skikda & $\ldots$ & 1 & $\ldots$ \\
\hline & Tiaret & 1 & $\ldots$ & $\ldots$ \\
\hline Israel & Tel Aviv & 1 & $\ldots$ & $\ldots$ \\
\hline \multirow[t]{3}{*}{ Morocco } & Doukkala & $\ldots$ & 1 & $\ldots$ \\
\hline & $\mathrm{Fez}$ & 1 & $\ldots$ & $\ldots$ \\
\hline & Jenica Shaim & $\ldots$ & 1 & $\ldots$ \\
\hline \multirow[t]{4}{*}{ The Netherlands } & Barendrecht & 1 & $\ldots$ & $\ldots$ \\
\hline & Ulrum & 1 & $\ldots$ & $\ldots$ \\
\hline & West Brabant & 1 & $\ldots$ & $\ldots$ \\
\hline & Zuid Flevoland & 1 & $\ldots$ & $\ldots$ \\
\hline \multirow[t]{2}{*}{ Portugal } & Casas Velhas & 2 & $\ldots$ & $\ldots$ \\
\hline & Elvas & 2 & $\ldots$ & 2 \\
\hline \multirow[t]{5}{*}{ Syria } & Derbasiyeh & $\ldots$ & 2 & $\ldots$ \\
\hline & Khou el Zarar & $\ldots$ & 1 & $\ldots$ \\
\hline & Lattakhia & 9 & 10 & 2 \\
\hline & Minbeg & 4 & 11 & $\ldots$ \\
\hline & Tel Aboid & $\ldots$ & 2 & $\ldots$ \\
\hline \multirow[t]{3}{*}{ Tunisia } & Beja & 1 & 2 & $\ldots$ \\
\hline & Nateur & $\ldots$ & 1 & $\ldots$ \\
\hline & Sidi Ncir & $\ldots$ & 1 & $\ldots$ \\
\hline \multirow[t]{4}{*}{ Turkey } & Adana & 4 & $\ldots$ & 1 \\
\hline & Altinova & $\ldots$ & 1 & $\ldots$ \\
\hline & Gönen & 1 & $\ldots$ & $\ldots$ \\
\hline & Tasci & 3 & $\ldots$ & $\ldots$ \\
\hline Totals & & 54 & 62 & 7 \\
\hline
\end{tabular}

${ }^{\mathrm{a}}$ Results were based on inoculation of four bread wheat and four durum wheat cultivars.

\section{MATERIALS AND METHODS}

Fungal isolates. Leaves infected with $M$. graminicola were collected from bread and durum wheat at 37 locations in eight countries around the Mediterranean Basin (Table 1). In two locations (Berrahal, Algeria and Lattakhia, Syria), infected leaves were sampled from both bread wheat and durum wheat. Isolations were made by collecting individual cirrhi with a sterile needle from single pycnidia after incubating the leaves for several hours in water-saturated air in a petri dish. Cirrhi were placed on V8 agar (commercially available Campbell's V8 vegetable juice solidified with $2.5 \%$ agar) and plates were stored in an incubator with $12 / 12$-h light/dark at $20^{\circ} \mathrm{C}$. In total, $123 \mathrm{M}$. graminicola isolates secured from the leaf samples were used in this study. Emerging colonies were inoculated into liquid yeast-glucose broth (YGB: yeast extract, $10 \mathrm{~g}$; glucose, $10 \mathrm{~g}$; in 1,000 ml of distilled water) and incubated in a reciprocal shaker at $18^{\circ} \mathrm{C}$ for 5 days. Conidia collected from V8 petri dishes and liquid medium were stored until use over silica gel at -80 and $-20^{\circ} \mathrm{C}$, respectively. Fungal inoculum was prepared by putting 2 to 10 silica-gel particles on yeast-glucose agar (yeast extract, $4 \mathrm{~g}$; glucose, $4 \mathrm{~g}$; and agar, $15 \mathrm{~g}$ in $1,000 \mathrm{ml}$ of distilled water) and transferring the emerging young $M$. graminicola colonies to 100 to $125 \mathrm{ml}$ of YGB in 250-ml Erlenmeyer flasks, which were shaken on a rotary shaker for 5 to 10 days at 17 to $20^{\circ} \mathrm{C}$, depending on the characteristics of the isolates. Some cultures grew fast and needed less shaking time (5 days). Others grew slowly and need more shaking time ( 7 to 10 days).

Pathogenicity assays. Inoculum (30-ml spore suspension adjusted to $1 \times 10^{7}$ spores per $\mathrm{ml}$ of distilled water using a Coulter [Counter Z1; Coulter Electronics Ltd., Luton, UK]) was supplemented with a drop of Tween 20 surfactant and applied with the revolving inoculation technique to 10 to 20 seedlings that were linearly planted in pots $(5 \times 5 \mathrm{~cm})$ per cultivar. Each isolate was inoculated onto bread wheat cvs. Gerek'79, Shafir, Ceeon, and Lakhish and durum wheat cvs. Volcani 447, Cakmak, Waha, and Zenati Bouteille. The latter cultivar was replaced by cv. Cocorit for some pathogenicity assays due to seed shortage. All bread wheat and durum wheat cultivars were highly susceptible to isolates originating from these respective species in previous experiments $(26,27)$. Pots were placed on a turntable rotating at $45 \mathrm{rpm}$ while inoculum was sprayed on the plants with an atomizer driven by compressed air. After inoculation, seedlings were allowed to dry for $30 \mathrm{~min}$, placed in one tray per isolate, and then placed in closed plastic bags in a greenhouse at $22^{\circ} \mathrm{C}(16 / 8$-h day/night rhythm), providing a saturated atmosphere to stimulate spore germination and plant penetration. After $48 \mathrm{~h}$, plastic bags were removed and plants were placed in the same greenhouse at $85 \%$ relative humidity until observation of symptoms (percent necrosis and pycnidia development) at 21 days after inoculation. Each isolate $\times$ cultivar combination was tested twice. The qualitative nature of responses of the two wheat species to M. graminicola enabled a quick and consistent identification of host specificity. Hence, all isolates could easily be categorized as being adapted to either bread wheat or durum wheat.

DNA extraction, restriction digestion, Southern blotting, and hybridization. For growth of isolates, flasks containing yeast sucrose broth (YSB: $10 \mathrm{~g}$ of yeast extract and $10 \mathrm{~g}$ of sucrose in $1,000 \mathrm{ml}$ of distilled water) were inoculated with a single-spore colony from each isolate. When the spore concentrations in the YSB reached approximately a mid-log growth phase, the fungal tissue was pelleted and stored at $-20^{\circ} \mathrm{C}$ before DNA was extracted. Total DNA from each isolate was extracted following a cetyltrimethylammonium bromide (CTAB) extraction protocol described previously (39). The concentrations of the DNA suspensions were measured by a DNA fluorometer (Hoefer TKO 100; Hoefer Scientific Instruments, San Francisco). Five micrograms of DNA from each isolate was digested with the re- 
striction enzyme PstI, and the DNA fragments were separated by electrophoresis through $0.8 \%$ agarose gels. DNA fragments in the agarose gels were transferred to nylon membranes (Bio-Rad Zeta Probe; Bio-Rad Laboratories, Hercules, CA) using alkaline capillary transfer. Afterward, the membranes were dried and stored in sealed plastic bags until needed.

Nine anonymous restriction fragment length polymorphism (RFLP) probes ( $p S T L 2, p S T L 10, p S T L 31, p S T L 53, p S T S 2, p S T S 14$, pSTS43, pSTS192, and pSTL70) chosen from a M. graminicola genomic library $(38,40)$ were used to hybridize to nuclear DNA of sample isolates. Probe $p S T L 70$ is a DNA fingerprinting probe able to distinguish genotypes of fungal isolates from each other. The entire mitochondrial DNA (mtDNA) genome was purified from a single fungal isolate, according to the method described by Garber and Yoder (20), and used as a probe to determine the mtDNA haplotypes of fungal strains. We found through a series of trials that a cesium chloride density of $1.6 \mathrm{~g} / \mathrm{ml}$ was optimal to separate nuclear and mitochondrial fractions of the M. graminicola genome.

The probes were radioactively labeled with $\mathrm{dCT}^{32} \mathrm{P}$ through nick translation according to the instructions of the manufacturer (Bio-Rad). The labeled probes were allowed to hybridize to the membranes overnight at $60^{\circ} \mathrm{C}$ in a hybridization incubator. Following hybridization, the membranes were washed and exposed to X-ray films placed between two intensifying screens at $-80^{\circ} \mathrm{C}$. The radioactive probes were stripped off the membranes after the films had been developed. Hybridization was repeated until all isolates had been probed with the $p S T L 70$ DNA fingerprint probe and eight other single-locus probes.

Data analysis. The isolates were placed into three groups based on the degree of pathogenicity displayed on bread wheat cultivars and durum wheat cultivars (Table 1). Each probe identified a different RFLP locus. An allele was defined as a DNA restriction fragment of specific molecular weight. mtDNA PstI RFLP patterns were considered mtDNA haplotypes. Allele frequencies were calculated for each locus for isolates adapted to bread or durum wheat. Multilocus haplotypes for each isolate were formed by joining the alleles present at each locus in the same order, forming a nine-digit number that described the haplotype for each isolate. Probe pSTL70 hybridized to several DNA fragments in each isolate, generating a profile of hybridizing fragments that was treated as a DNA fingerprint (40). Isolates with the same DNA fingerprint, multilocus haplotype, and mtDNA haplotype were considered individual members of the same clone, the products of asexual reproduction. To prevent a bias in allele frequencies caused by repeated sampling of the same clone in any population, clone-corrected allele frequencies were calculated for each RFLP locus by using only one representative from each clone. Clone-corrected allele frequencies were used to estimate all population genetic parameters.

Genotype diversity was estimated with Stoddart and Taylor's method (52). Genetic variation in each collection was quantified using measures of gene diversity (45). Contingency chi-square tests (56) were used to assess differences in allele frequencies between M. graminicola collections made from the two hosts. For these tests, alleles present at frequencies lower than 0.05 were pooled into a single category. Nei's measures of population differentiation (45) and genetic distance (44) were calculated to examine interpopulation diversity between bread wheat and durum wheat populations.

\section{RESULTS}

Pathogenicity tests. The susceptibility of bread wheat cvs. Gerek'79, Shafir, Ceeon, and Lakhish and durum wheat cvs. Volcani 447, Cakmak, Waha, Zenati Bouteille, and Cocorit to bread wheat and durum wheat isolates, respectively, was confirmed. In the majority of cases, the $123 \mathrm{M}$. graminicola isolates induced only characteristic symptoms in the wheat species (bread and durum wheat) from which they originated, even when isolates originated from the same locations. Only 7 of the $123(6 \%)$ isolates tested were able to induce symptoms on both wheat species (Table 1). RFLP data were not available for any of these isolates.

Genetic variation in nuclear and mitochondrial genome. Forty-seven distinct genotypes were identified among the 52 isolates assayed for RFLPs and sampled from bread wheat. Among these isolates, one genotype was observed three times, three were found twice, and the remaining 43 genotypes were observed once. Stoddart's measure of genotype diversity in this sample was $42.2 \pm 5.2$, which was $81 \%$ of the maximum possible value of 52 . Fifty-four genotypes were detected among the 56 isolates assayed for RFLPs and sampled from durum wheat. Among these isolates, two genotypes were observed twice and all other genotypes were observed once. Stoddart's measure of genotype diversity in this sample was $52.3 \pm 3.4$, which was $93 \%$ of the maximum possible value of 56. No identical genotypes were detected among isolates sampled from different geographic locations and hosts.

The number of alleles found at the nine nuclear RFLP loci ranged from 1 to 9 with an average of 4.4 alleles per locus in the isolates adapted to bread wheat and 4.6 per locus in the isolates adapted to durum wheat (Table 2). The number of private alleles found at the nine nuclear RFLP loci ranged from 1 to 3 with an average of 1.3 per locus in the isolates sampled from bread wheat and 0.8 per locus in the isolates sampled from durum wheat (Table 2). The host-specialized populations had similar levels of genetic diversity. For the nine nuclear loci, the gene diversity within populations ranged from 0.00 to 0.81 with an average of 0.38 in the fungal population specializing to bread wheat and 0.00 to 0.74 with an average of 0.39 in the fungal population specializing to durum wheat (Table 2).

Six different mtDNA haplotypes were found among the 108 isolates surveyed (Fig. 1). Stoddart's measure of genotype diversity for mitochondrial haplotypes in the sample adapted to bread

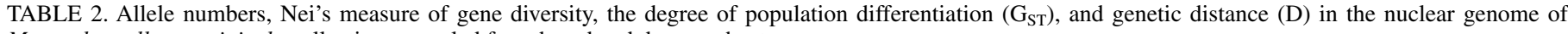
Mycosphaerella graminicola collections sampled from bread and durum wheat

\begin{tabular}{|c|c|c|c|c|c|c|c|c|}
\hline \multirow{2}{*}{$\begin{array}{l}\text { Nuclear restriction fragment } \\
\text { length polymorphism loci }\end{array}$} & \multicolumn{2}{|c|}{ Total alleles } & \multicolumn{2}{|c|}{ Private alleles } & \multicolumn{2}{|c|}{ Gene diversity } & \multirow[b]{2}{*}{$\mathrm{G}_{\mathrm{ST}}$} & \multirow[b]{2}{*}{$\mathrm{D}$} \\
\hline & Bread & Durum & Bread & Durum & Bread & Durum & & \\
\hline pSTL2-PstI & 3 & 3 & 1 & 1 & 0.21 & 0.27 & 0.004 & 0.002 \\
\hline$p S T L 10-P s t \mathrm{I}$ & 7 & 4 & 3 & 0 & 0.60 & 0.35 & 0.049 & 0.069 \\
\hline$p S T L 53-P s t \mathrm{I}$ & 6 & 7 & 1 & 2 & 0.68 & 0.72 & 0.022 & 0.107 \\
\hline$p S T L 31-P s t \mathrm{I}$ & 8 & 9 & 2 & 1 & 0.81 & 0.74 & 0.047 & 0.394 \\
\hline$p S T S 2-P s t \mathrm{I}$ & 3 & 3 & 0 & 0 & 0.27 & 0.36 & 0.006 & 0.003 \\
\hline pSTS14-PstI & 3 & 3 & 1 & 1 & 0.25 & 0.21 & 0.005 & 0.002 \\
\hline pSTS43-PstI & 6 & 8 & 2 & 0 & 0.46 & 0.67 & 0.020 & 0.026 \\
\hline pSTS192A-PstI & 3 & 3 & 2 & 2 & 0.12 & 0.16 & 0.011 & 0.003 \\
\hline$p S T S 192 \mathrm{~B}-P s t \mathrm{I}$ & 1 & 1 & 0 & 0 & 0.00 & 0.00 & 0.000 & 0.000 \\
\hline Average & 4.4 & 4.6 & 1.3 & 0.8 & 0.38 & 0.39 & 0.018 & 0.061 \\
\hline
\end{tabular}


wheat was $2.8 \pm 0.4$, which was $6 \%$ of the theoretical maximum. Stoddart's measure of genotype diversity for mitochondrial haplotypes in the sample adapted to durum wheat was $3.3 \pm 0.4$, which was also $6 \%$ of the theoretical maximum. Restriction mapping (data not shown) revealed that the differences among the mtDNA haplotypes were due to insertion or deletion events (Fig. 1). The mtDNA haplotypes 4 and 6 contained a $4.7-\mathrm{kb}$ fragment with a $3.0-\mathrm{kb}$ insertion that was not present in the other mtDNA haplotypes. When mtDNA haplotypes 4 and 6 were probed with DNA from mtDNA haplotypes 1 and 3, hybridization of the $4.7-\mathrm{kb}$ fragment was weaker than the hybridization to all other fragments. When mtDNA haplotypes 4 and 6 were probed with purified mtDNA from haplotype 4 , the hybridization intensity was equal for all fragments.

Population subdivision between M. graminicola populations from bread and durum wheat. Fungal isolates adapted to bread wheat and durum wheat shared all common alleles in the nuclear genome (Table 3). The hypothesis of equal allele frequencies between the two fungal populations was not rejected for eight of the nine nuclear RFLP loci surveyed. The level of population differentiation between the two fungal populations, as measured by $\mathrm{G}_{\mathrm{ST}}$, ranged from 0.00 to 0.05 with an average of 0.02 in the nuclear genome. Nei's measurement of genetic distance ranged from 0.00 to 0.39 with an average of 0.06 (Table 2).

The frequencies of mtDNA haplotypes differed significantly between isolates adapted to the two wheat species $(P<0.0001$; Table 4). mtDNA haplotype 1 dominated on the isolates adapted to bread wheat, and its frequency was twice as high as in the population adapted to durum wheat. mtDNA haplotype 4 predominated on isolates adapted to durum wheat and was not found among the isolates adapted to bread wheat. $\mathrm{G}_{\mathrm{ST}}$ and genetic distance for the mitochondrial genome in the host-specialized populations were 0.08 and 0.46 , respectively.

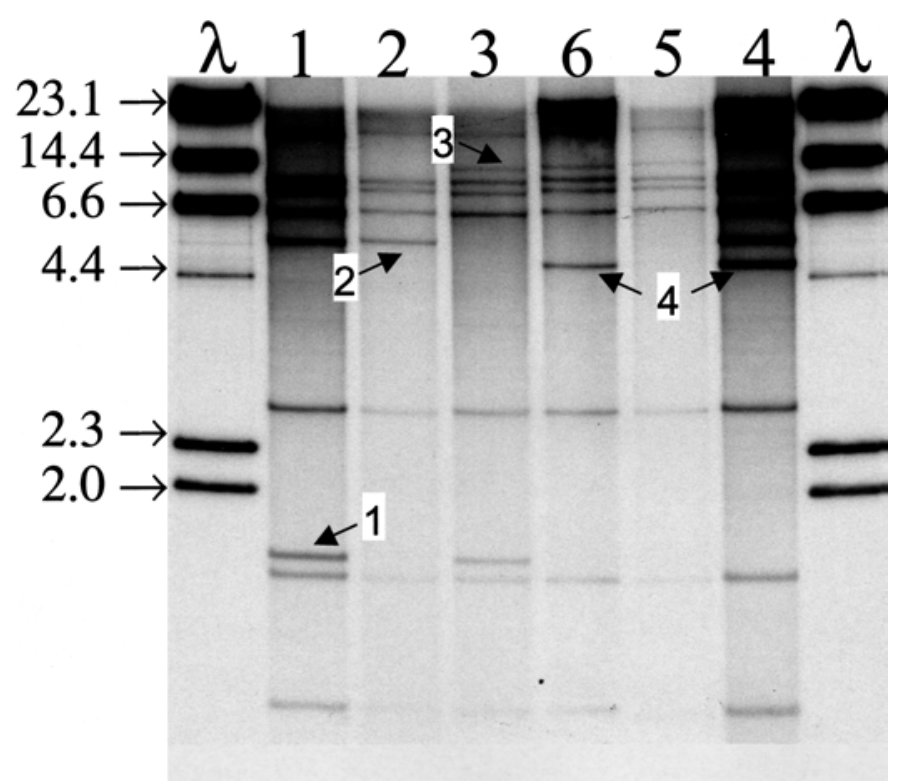

Fig. 1. An autoradiogram showing the Pst I restriction fragment length polymorphism patterns of six of the seven mitochondrial DNA (mtDNA) haplotypes found in the global population of Mycosphaerella graminicola. Entire mtDNA purified from a type 4 strain was hybridized to the mitochondrial genome of sample strains. Type 2 differs from type 1 by a deletion of the $1.7-\mathrm{kb}$ fragment indicated by arrow 1 . Type 3 differs from type 1 by a $3.5-\mathrm{kb}$ insertion in the 5.2-kb fragment indicated by arrow 2 that creates the $8.7-\mathrm{kb}$ fragment indicated by arrow 3 . Type 5 differs from type 1 by a combination of the two events that occurred in type 2 and type 3 . Type 4 differs from type 1 by a $3-\mathrm{kb}$ insertion in the $1.7-\mathrm{kb}$ fragment indicated by arrow 1 that gives rise to the fragment indicated by arrow 4 . Type 6 differs from type 3 by a $3-\mathrm{kb}$ insertion in the $1.7-\mathrm{kb}$ fragment indicated by arrow 1 that gives rise to the fragment indicated by arrow 4 .

\section{DISCUSSION}

In the few fungi studied to date, genetic variation in the mtDNA genome is usually concordant with genetic variation in the nuclear genome. For example, Agaricus bisporus, Cryphonectria parasitica, Phaeosphaeria nodorum, and Sclerotinia sclerotiorum were characterized by high levels of nuclear diversity (25, $32,35,58)$, and their mitochondrial genomes also displayed a high level of genetic variation $(32,35,41,59)$. On the other hand, populations of Ceratocystis fagacearum, Magnaporthe grisea, and Phytophthora infestans usually exhibited low gene and genotype diversity in their nuclear genomes $(15,22,33)$. Consistent with these findings, little mitochondrial variation was detected in these fungi $(11,57)$. The $M$. graminicola population from the Mediterranean Basin did not follow this pattern of genetic variation. Fungal populations originating from this region had a high degree of diversity in the nuclear genome. The great majority (101/108)

TABLE 3. Allele frequencies and $\chi^{2}$ tests for homogeneity in allele frequency between Mycosphaerella graminicola collections sampled from bread and durum wheat ${ }^{\mathrm{a}}$

\begin{tabular}{|c|c|c|c|c|}
\hline \multirow{2}{*}{$\begin{array}{l}\text { Nuclear restriction fragment } \\
\text { length polymorphism loci }\end{array}$} & \multirow[b]{2}{*}{ Allele } & \multicolumn{2}{|c|}{ Hosts } & \multirow[b]{2}{*}{$\chi^{2}$ value $(\mathrm{df})$} \\
\hline & & Bread & Durum & \\
\hline \multirow[t]{2}{*}{ pSTL2-PstI } & 5 & 0.88 & 0.85 & \\
\hline & 9 & 0.10 & 0.13 & $2.23(3)$ \\
\hline \multirow[t]{4}{*}{ pSTL10-PstI } & 1 & 0.55 & 0.79 & \\
\hline & 3 & 0.31 & 0.13 & \\
\hline & 13 & 0.05 & 0.00 & \\
\hline & 19 & 0.02 & 0.05 & $8.98(6)$ \\
\hline \multirow[t]{5}{*}{ pSTL53-PstI } & 1 & 0.48 & 0.37 & \\
\hline & 2 & 0.11 & 0.29 & \\
\hline & 3 & 0.11 & 0.00 & \\
\hline & 6 & 0.26 & 0.24 & \\
\hline & 8 & 0.00 & 0.06 & $11.28(5)^{*}$ \\
\hline \multirow[t]{8}{*}{ pSTL31-PstI } & 2 & 0.34 & 0.11 & \\
\hline & 4 & 0.07 & 0.03 & \\
\hline & 5 & 0.17 & 0.46 & \\
\hline & 6 & 0.17 & 0.11 & \\
\hline & 11 & 0.00 & 0.05 & \\
\hline & 13 & 0.07 & 0.14 & \\
\hline & 18 & 0.07 & 0.05 & \\
\hline & 22 & 0.05 & 0.05 & $16.08(9)$ \\
\hline \multirow[t]{3}{*}{ pSTS2-PstI } & 1 & 0.85 & 0.78 & \\
\hline & 3 & 0.10 & 0.16 & \\
\hline & 4 & 0.05 & 0.05 & $0.61(2)$ \\
\hline \multirow[t]{3}{*}{$p S T S 14-P s t \mathrm{I}$} & 1 & 0.86 & 0.88 & \\
\hline & 2 & 0.08 & 0.10 & \\
\hline & 7 & 0.06 & 0.00 & $3.23(3)$ \\
\hline \multirow[t]{6}{*}{ pSTS43-PstI } & 1 & 0.72 & 0.54 & \\
\hline & 2 & 0.08 & 0.09 & \\
\hline & 3 & 0.05 & 0.07 & \\
\hline & 5 & 0.10 & 0.07 & \\
\hline & 6 & 0.03 & 0.07 & \\
\hline & 11 & 0.00 & 0.11 & $7.46(7)$ \\
\hline pSTS192A-PstI & 1 & 0.94 & 0.92 & $4.21(4)$ \\
\hline$p S T S 192 \mathrm{~B}-P s t \mathrm{I}$ & 1 & 1.00 & 1.00 & - \\
\hline
\end{tabular}

a Alleles with frequencies lower than 0.05 in both collections were not listed.

* Indicates significant at $P=0.05$.

TABLE 4. Frequencies of mitochondrial DNA (mtDNA) haplotypes in the Mycosphaerella graminicola populations sampled from bread wheat and durum wheat and $\chi^{2}$ tests for homogeneity in haplotype frequencies between the fungal populations

\begin{tabular}{lccc}
\hline mtDNA haplotypes & Bread wheat & Durum wheat & $\chi^{2}$ value $(\mathrm{df})$ \\
\hline 1 & 0.50 & 0.21 & \\
2 & 0.06 & 0.02 & \\
3 & 0.33 & 0.27 & \\
4 & 0.00 & 0.43 & \\
5 & 0.02 & 0.04 & $31.8(5)^{\mathrm{a}}$ \\
6 & 0.09 & 0.04 & 3 \\
\hline
\end{tabular}

a Significant at $P=0.0001$. 
of fungal isolates had unique nuclear genotypes as indicated by DNA fingerprints and multilocus haplotypes. In contrast, mtDNA haplotype variation was very low. Only six haplotypes were detected in the 108 isolates studied. This finding was consistent with other results based on a larger data set (63) that included nearly 1,700 isolates sampled from wheat fields on five continents. On average, we detected 18 alleles across the eight RFLP loci in the nuclear genome, and the majority of isolates sampled from the same field had different DNA fingerprints and multilocus haplotypes (63). On the other hand, only seven mtDNA haplotypes were found and the two most common haplotypes made up more than $90 \%$ of the global M. graminicola population.

Several hypotheses could explain the low mtDNA diversity found in $M$. graminicola populations worldwide. First, the low mtDNA variation in this fungus could be a result of genetic drift. Drift may be common for pathogenic fungi in agricultural systems due to repeating epidemic cycles characterized by substantial expansion and contraction in population size. A bottleneck can occur at the end of an epidemic cycle if only a small number of genotypes survive to initiate the next epidemic. Previous studies of diversity using the same nuclear RFLP loci indicated that $M$. graminicola field populations are large, with effective sizes ranging from several thousand to several hundred thousand individuals (62). Thus, we believe that effective population sizes are large enough to offset the random effects of genetic drift. Furthermore, since drift should affect nuclear and mitochondrial genomes equally in haploid organisms, the random drift hypothesis is contrary to the finding of so many alleles at the nuclear RFLP loci in this collection of isolates, as well as the larger collection reported earlier (63).

A second explanation for low mtDNA variation is lower rates of mutation in the mitochondrial genome compared with the nuclear genome in fungi. In contrast to mammals, the rate of base substitution is much lower in the mitochondrial genome of yeast than in its counterpart nuclear genome $(13,48)$. Clark-Walker $(14)$ hypothesized that other fungal species would display a similar pattern of evolution. When we sequenced random regions of the mitochondrial genome, we found less site polymorphism compared with that of the nuclear genome (S. Banke, personal communication). We should point out that this result is also consistent with nonneutral evolution of the mitochondrial genome.

The most plausible explanation for the observed low mtDNA haplotype variation, however, is natural selection. It has been shown that mitochondrial genomes contain many genes vital for the survival and reproduction of organisms (50) and that the evolution of the mitochondrial genome is not neutral $(5,43)$, partially due to the adaptation of the mitochondrial genome and/or specific nucleo-mitochondrial gene complexes to the local environment (4). For pathogenic microorganisms, this environment can be biotic (e.g., genetic constitution of the hosts) and abiotic (e.g., demography of the hosts). It is possible that in M. graminicola, mitochondrial genomes contain factors directly or indirectly required for host specialization and/or the adaptation to abiotic environments. Changes in cultural practices inherent in modern agriculture have imposed strong selection on the mitochondrial genome in fungal pathogens.

Modern agriculture is characterized by the widespread use of cultivars with high yield potential and disease resistance. The novel resistance genes introduced into modern cultivars may impose strong selection against fungal strains with wild-type mitochondria, and new mutants that survive this antagonistic host environment could quickly emerge from the selected populations. Modern agriculture is also characterized by high-density monocultures often composed of a single plant genotype. The trade-off between aggressiveness (virulence is the equivalent term used by evolutionary biologists) and transmission of pathogens is expected to be different in modern agroecosystems and natural ecosystems. In an agroecosystem based on a single host genotype planted at a high density, natural selection could favor fungal mutants with faster metabolic rates because they would complete the disease cycle and reproduce more quickly than wild-type strains with slower metabolic rates. Mutant strains with faster metabolic rates would colonize the host more quickly, have shorter latent periods, and leave more offspring in a shorter period of time than wild-type strains with a lower metabolic rate, setting the stage for a selective sweep in a modern agroecosystem. If the faster metabolic rate also leads to higher aggressiveness (virulence), the likely result is increased damage to the plant host over a shorter period of time compared with pathogen strains with regular metabolic rates. However, if the host is damaged too quickly, the pathogen will not achieve its maximal reproductive output and the result would be a decrease in transmission rate of the mutant pathogen with higher metabolism compared with the wild-type pathogen strain. Because of the high host density and genetic uniformity of modern agroecosystems, pathogen populations can maintain a higher level of aggressiveness without a corresponding trade-off in decreased transmissiveness. In natural ecosystems characterized by lower host density and greater host diversity, strains with faster metabolic rates are likely to be selected against because they would damage the host too quickly to provide an optimal transmission rate.

Unlike their nuclear counterparts, most mitochondrial genomes $(7,47)$, including M. graminicola (G. H. J. Kema and B. A. McDonald, unpublished data), display uniparental inheritance and limited recombination. Thus, directional selection for any mtDNA mutation that imparts desirable ecological and physiological traits would select the entire linked mitochondrial haplotype. Once a haplotype with higher fitness emerges, it can move among regional populations by gene flow through wind-blown ascospores and possibly among continents by the global trade in wheat. If the new mutant mtDNA haplotype has higher fitness in each agricultural ecosystem, only isolates that contain the new mutant mtDNA haplotype would survive from the antagonistic environments. The result would be a substantial decrease in the mtDNA diversity in agricultural populations due to a selective sweep.

If this is true, mtDNA haplotype 1 is most likely the haplotype that drove the selective sweep. The other mitochondrial haplotypes emerged from mtDNA type 1 through a series of deletion and insertion events. mtDNA haplotype 4 may have originated from type 1 by insertion of the $3.0-\mathrm{kb}$ fragment into the original $1.7-\mathrm{kb}$ fragment. We consider it unlikely that the $3.0-\mathrm{kb}$ insertion contains a novel gene that increases parasitic fitness on durum wheat. It more likely contains alleles that interact with nuclear genes (or subunits) closely linked to a host specificity factor located in the nuclear genome.

We have two lines of evidence to support the hypothesis that natural selection is operating on the mitochondrial genome of $M$. graminicola. The first line of evidence is from the analysis of host specificity provided in this study. When pathogen populations were compared across the two hosts, we found that the fungal isolates adapted to bread wheat differed significantly from those adapted to durum wheat in the frequency of mtDNA haplotypes (Table 4). This nonrandom association between mitochondrial haplotypes and host species in $M$. graminicola is consistent with previous findings for fungi $(16,21)$, insects (2), nematodes (64), and protozoa (6). The difference in mtDNA haplotype frequency between the two host-adapted fungal populations is not likely to be due to reproductive isolation because there was little evidence for population subdivision in the nuclear genome. The probes used in this study were cloned from an isolate adapted to bread wheat, and they hybridized equally well to isolates from durum wheat. Analysis of gene frequency showed that the two fungal populations shared all common alleles and the average genetic distance across the nine nuclear loci was low (Tables 2 and 3). We consider it highly unlikely these two fungal populations would 
appear so similar in the nuclear genome if they were reproductively isolated in nature. We also found that DNA sequences of mating type idiomorphs and internal transcribed spacer regions were very similar between bread wheat isolates and durum wheat isolates (G. H. J. Kema, unpublished data). When we used mating type-specific primers designed from the DNA sequences of bread wheat isolates to amplify durum wheat isolates, the amplicons were clear and their sizes were identical to those produced from bread wheat isolates (55). Finally, we successfully crossed bread wheat- and durum wheat-adapted strains in planta, showing that these populations conform to the biological species concept (G. H. J. Kema, unpublished data).

The second line of evidence for selection comes from analysis of the spatial distribution of mtDNA haplotypes. Though the number of haplotypes is limited, we found a significant difference in the frequency of mtDNA haplotypes $(P<0.0001)$ among fungal populations originating from different geographic locations (Table 4 in literature citation 63), suggesting a nonrandom spatial distribution in mtDNA haplotypes. The finding of a nonrandom spatial distribution in mtDNA haplotypes is also consistent with observations in Phaeosphaeria nodorum (B. A. McDonald, unpublished data) and other species (3). Previous findings are consistent with a high degree of gene flow for the nuclear genome of $M$. graminicola (63), and we believe that the nonrandom spatial distribution of mtDNA haplotypes is not due to genetic drift resulting from geographical isolation. Rather, we believe that heterogeneity in population structure of mtDNA haplotypes is due to natural selection operating in local environments (i.e., local adaptation). This selection may at least partially reflect host specificity in intensively managed wheat monocultures that favor mtDNA haplotypes with higher metabolic rates.

\section{ACKNOWLEDGMENTS}

This project was funded by the National Science Foundation DEB9306377, the Swiss Federal Institute of Technology (ETH), Zurich (TH36/00-1), and the Dutch Ministry of Agriculture, Nature Management and Food Safety. We thank K. Hogan, G. Trautweiler, and R. Pettway at Texas A\&M University; M. Zala in the Phytopathology group, ETH at Zurich; M.-R. Simón at La Plata University, Argentina; and the Wageningen Mycosphaerella Group at Plant Research International and Wageningen University, The Netherlands, for collecting most of the molecular and pathogenicity data.

\section{LITERATURE CITED}

1. Ahmed, U. H., Mundt, C. C., Hoffer, M. E., and Coakley, S. M. 1996. Selective influence of wheat cultivars on pathogenicity of Mycosphaerella graminicola (anamorph Septoria tritici). Phytopathology 86:454-458.

2. Anstead, J. A., Burd, J. D., and Shufran, K. A. 2002. Mitochondrial DNA sequence divergence among Schizaphis graminum (Hemiptera: Aphididae) clones from cultivated and non-cultivated hosts: Haplotype and host associations. Bull. Entomol. Res. 92:17-24.

3. Avise, J. C., Arnold, J., Ball, R. M., Bermingham, E., Lamb, T., Neigel, J. E., Reeb, C. A., and Saunders, N. C. 1987. Intraspecific phylogeographythe mitochondrial DNA bridge between population genetics and systematics. Annu. Rev. Ecol. Syst. 18:489-522.

4. Ballard, J. W. O., Chernoff, B., and James, A. C. 2002. Divergence of mitochondrial DNA is not corroborated by nuclear DNA, morphology, or behavior in Drosophila simulans. Evolution 56:527-545.

5. Ballard, J. W. O., and Kreitman, M. 1994. Unraveling selection in the mitochondrial genome of Drosophila. Genetics 138:757-772.

6. Bensch, S., Stjernman, M., Hasselquist, D., Ostman, O., Hansson, B., Westerdahl, H., and Pinheiro, R. T. 2000. Host specificity in avian blood parasites: A study of Plasmodium and Haemoproteus mitochondrial DNA amplified from birds. Proc. R. Soc. Lon. Series B-Biol. Sci. 267:1583-1589.

7. Birky, C. W. 1995. Uniparental inheritance of mitochondrial and chloroplast genes-mechanisms and evolution. Proc. Natl. Acad. Sci. USA 92: 11331-11338.

8. Brading, P. A., Verstappen, E. C. P., Kema, G. H. J., and Brown, J. K. M. 2002. A gene-for-gene relationship between wheat and Mycosphaerella graminicola, the Septoria tritici blotch pathogen. Phytopathology 92: 439-445.
9. Brokenshire, T. 1975. The role of Graminaceous species in the epidemiology of Septoria tritici on wheat. Plant Pathol. 24:33-38.

10. Bruns, T. D., White, T. J., and Taylor, J. W. 1991. Fungal molecular systematics. Annu. Rev. Ecol. Syst. 22:525-564.

11. Carlisle, D. J., Cooke, L. R., and Brown, A. E. 2001. Phenotypic and genotypic characterisation of Northern Ireland isolates of Phytophthora infestans. Eur. J. Plant Pathol. 107:291-303.

12. Chen, R. S., and McDonald, B. A. 1996. Sexual reproduction plays a major role in the genetic structure of populations of the fungus Mycosphaerella graminicola. Genetics 142:1119-1127.

13. Clark-Walker, G. D. 1991. Contrasting mutation rates in mitochondrial and nuclear genes of yeasts versus mammals. Curr. Genet. 20:195-198.

14. Clark-Walker, G. D. 1992. Evolution of mitochondrial genomes in fungi. Int. Rev. Cytol. 141:69-127.

15. Correll, J. C., Harp, T. L., Guerber, J. C., Zeigler, R. S., Liu, B., Cartwright, R. D., and Lee, F. N. 2000. Characterization of Pyricularia grisea in the United States using independent genetic and molecular markers. Phytopathology 90:1396-1404.

16. Demanche, C., Berthelemy, M., Petit, T., Polack, B., Wakefield, A. E., Dei-Cas, E., and Guillot, J. 2001. Phylogeny of Pneumocystis carinii from 18 primate species confirms host specificity and suggests coevolution. J. Clin. Microbiol. 39:2126-2133.

17. Eyal, Z. 1999. The Septoria tritici and Stagonospora nodorum blotch diseases of wheat. Eur. J. Plant Pathol. 105:629-641.

18. Eyal, Z., Scharen, A. L., Huffman, M. D., and Prescott, J. M. 1985. Global insights into virulence frequencies of Mycosphaerella graminicola. Phytopathology 75:1456-1462.

19. Filatov, D. A., Laporte, V., Vitte, C., and Chartesworth, D. 2001. DNA diversity in sex-linked and autosomal genes of the plant species Silene latifolia and Silene dioica. Mol. Biol. Evol. 18:1442-1454.

20. Garber, R. C., and Yoder, O. C. 1983. Isolation of DNA from filamentous fungi and separation into nuclear, mitochondrial, ribosomal, and plasmid components. Analyt. Biochem. 135:416-422.

21. Gomes, E. A., de Abreu, L. M., Borges, A. C., and de Araujo, E. F. 2000. ITS sequences and mitochondrial DNA polymorphism in Pisolithus isolates. Mycol. Res. 104:911-918.

22. Goodwin, S. B., Cohen, B. A., and Fry, W. E. 1994. Panglobal distribution of a single clonal lineage of the Irish potato famine fungus. Proc. Natl. Acad. Sci. USA 91:11591-11595.

23. Hartl, D. L., and Clark, A. G. 1997. Principles of Population Genetics. Sinauer Associates, Sunderland, MA.

24. Hunter, T., Coker, R. R., and Royle, D. J. 1999. The teleomorph stage, Mycosphaerella graminicola, in epidemics of septoria tritici blotch on winter wheat in the UK. Plant Pathol. 48:51-57.

25. Keller, S. M., McDermott, J. M., Pettway, R. E., Wolfe, M. S., and McDonald, B. A. 1997. Gene flow and sexual reproduction in the wheat glume blotch pathogen Phaeosphaeria nodorum (anamorph Stagonospora nodorum). Phytopathology 87:353-358.

26. Kema, G. H. J., Annone, J. G., Sayoud, R., van Silfhout, C. H., van Ginkel, M., and de Bree, J. 1996. Genetic variation for virulence and resistance in the wheat-Mycosphaerella graminicola pathosystem. I. Interactions between pathogen isolates and host cultivars. Phytopathology 86:200-212.

27. Kema, G. H. J., Sayoud, R., Annone, J. G., and van Silfhout, C. H. 1996. Genetic variation for virulence and resistance in the wheat-Mycosphaerella graminicola pathosystem. II. Analysis of interactions between pathogen isolates and host cultivars. Phytopathology 86:213-220.

28. Kema, G. H. J., and van Silfhout, C. H. 1997. Genetic variation for virulence and resistance in the wheat-Mycosphaerella graminicola pathosystem. III. Comparative seedling and adult plant experiments. Phytopathology 87:266-272.

29. Kema, G. H. J., Verstappen, E. C. P., Todorova, M., and Waalwijk, C. 1996. Successful crosses and molecular tetrad and progeny analyses demonstrate heterothallism in Mycosphaerella graminicola. Curr. Genet. 30:251-258.

30. Kema, G. H. J., Verstappen, E. C. P., and Waalwijk, C. 2000. Avirulence in the wheat Septoria tritici leaf blotch fungus Mycosphaerella graminicola is controlled by a single locus. Mol. Plant-Microbe Interact. 13: 1375-1379.

31. Kohli, Y., and Kohn, L. M. 1996. Mitochondrial haplotypes in populations of the plant-infecting fungus Sclerotinia sclerotiorum: Wide distribution in agriculture, local distribution in the wild. Mol. Ecol. 5:773-783.

32. Kudla, J., Albertazzi, F. J., Blazevic, D., Hermann, M., and Bock, R. 2002. Loss of the mitochondrial cox 2 intron 1 in a family of monocotyledonous plants and utilization of mitochondrial intron sequences for the construction of a nuclear intron. Mol. Genet. Genomics 267:223-230.

33. Kurdyla, T. M., Guthrie, P. A. I., McDonald, B. A., and Appel, D. N. 1995. RFLPs in mitochondrial and nuclear DNA indicate low levels of genetic diversity in the oak wilt pathogen Ceratocystis fagacearum. Curr. Genet. 27:373-378. 
34. Leung, H., Nelson, R. J., and Leach, J. E. 1993. Population structure of plant pathogenic fungi and bacteria. Pages 157-205 in: Advances in Plant Pathology. J. H. Andrews and I. C. Tommerup, eds. Academic Press, New York.

35. Liu, Y. C., Cortesi, P., Double, M. L., MacDonald, W. L., and Milgroom, M. G. 1996. Diversity and multilocus genetic structure in populations of Cryphonectria parasitica. Phytopathology 86:1344-1351.

36. McCartney, C. A., Brule-Babel, A. L., and Lamari, L. 2002. Inheritance of race specific resistance to Mycosphaerella graminicola in wheat. Phytopathology 92:138-144.

37. McDonald, B. A., and Linde, C. 2002. Pathogen population genetics, evolutionary potential, and durable resistance. Annu. Rev. Phytopathol. 40:349-379.

38. McDonald, B. A., and Martinez, J. P. 1990. Restriction fragment length polymorphisms in Septoria tritici occur at a high frequency. Curr. Genet. 17:133-138.

39. McDonald, B. A., and Martinez, J. P. 1991. Chromosome length polymorphisms in a Septoria tritici population. Curr. Genet. 19:265-271.

40. McDonald, B. A., and Martinez, J. P. 1991. DNA fingerprinting of the plant pathogenic fungus Mycosphaerella graminicola (anamorph Septoria tritici). Exp. Mycol. 15:146-158.

41. McDonald, B. A., Zhan, J., Yarden, O., Hogan, K., Garton, J., and Pettway, R. E. 1999. The population genetics of Mycosphaerella graminicola and Phaeosphaeria nodorum. Pages 44-69 in: Septoria on Cereals: A Study of Pathosystems. J. A. Lucas, P. Bowyer, and H. M. Anderson, eds. CAB International, Wallingford, UK.

42. Milgroom, M. G., and Lipari, S. E. 1995. Population differentiation in the chestnut blight fungus, Cryphonectria parasitica, in eastern North America. Phytopathology 85:155-160.

43. Nachman, M. W., Boyer, S. N., and Aquadro, C. F. 1994. Nonneutral evolution at the mitochondrial NADH dehydrogenase subunit 3 gene in mice. Proc. Natl. Acad. Sci. USA 91:6364-6368.

44. Nei, M. 1972. Genetic distance between populations. Am. Nat. 106:283292.

45. Nei, M. 1973. Analysis of gene diversity in subdivided populations. Proc. Natl. Acad. Sci. USA 70:3321-3323.

46. Rundle, H. D. 2002. A test of ecologically dependent postmating isolation between sympatric sticklebacks. Evolution 56:322-329.

47. Russell, P. J. 1996. Genetics. Harper Collins College Publishers, New York.

48. Saliola, M., Shuster, J. R., and Falcone, C. 1990. The alcohol dehydrogenase system in the yeast, Kluyveromyces lactis. Yeast 6:193-204.

49. Saville, B. J., Kohli, Y., and Anderson, J. B. 1998. mtDNA recombination in a natural population. Proc. Natl. Acad. Sci. USA 95:1331-1335.

50. Sekito, T., Okamoto, K., Kitano, H., and Yoshida, K. 1995. The complete mitochondrial DNA sequence of Hansenula wingei reveals new characteristics of yeast mitochondria. Curr. Genet. 28:39-53
51. Staskawicz, B. J., Ausubel, F. M., Baker, B. J., Ellis, J. G., and Jones, J. D. G. 1995. Molecular genetics of plant disease resistance. Science 268:661-667.

52. Stoddart, J. A., and Taylor, J. F. 1988. Genotypic diversity: Estimation and prediction in samples. Genetics 118:705-711.

53. Van Ginkel, M., and Scharen, A. L. 1988. Host-pathogen relationships of wheat and Septoria tritici. Phytopathology 78:762-766.

54. Vigouroux, Y., McMullen, M., Hittinger, C. T., Houchins, K., Schulz, L., Kresovich, S., Matsuoka, Y., and Doebley, J. 2002. Identifying genes of agronomic importance in maize by screening microsatellites for evidence of selection during domestication. Proc. Natl. Acad. Sci. USA 99:96509655.

55. Waalwijk, C., Mendes, O., Verstappen, E. C. P., de Waard, M. A., and Kema, G. H. J. 2002. Isolation and characterization of the mating-type idiomorphs from the wheat Septoria leaf blotch fungus Mycosphaerella graminicola. Fungal Genet. Biol. 35:277-286.

56. Workman, P. L., and Niswander, J. D. 1970. Population studies on Southwestern Indian tribes. II. Local genetic differentiation in the Papago. Am. J. Hum. Genet. 22:24-49.

57. Xia, J. Q., Correll, J. C., Lee, F. N., Ross, W. J., and Rhoads, D. D. 2000. Regional population diversity of Pyricularia grisea in Arkansas and the influence of host selection. Plant Dis. 84:877-884.

58. Xu, J., Kerrigan, R. W., Callac, P., Horgen, P. A., and Anderson, J. B. 1997. Genetic structure of natural populations of Agaricus bisporus, the commercial button mushroom. J. Hered. 88:482-488.

59. Xu, J. P., Kerrigan, R. W., Sonnenberg, A. S., Callac, P., Horgen, P. A., and Anderson, J. B. 1998. Mitochondrial DNA variation in natural populations of the mushroom Agaricus bisporus. Mol. Ecol. 7:19-23.

60. Zhan, J., Mundt, C. C., Hoffer, M. E., and McDonald, B. A. 2002. Local adaptation and effect of host genotype on the evolution of pathogens: An experimental test in a plant pathosystem. J. Evol. Biol. 15:634-647.

61. Zhan, J., Mundt, C. C., and McDonald, B. A. 1998. Measuring immigration and sexual reproduction in field populations of Mycosphaerella graminicola. Phytopathology 88:1330-1337.

62. Zhan, J., Mundt, C. C., and McDonald, B. A. 2001. Using restriction fragment length polymorphisms to assess temporal variation and estimate the number of ascospores that initiate epidemics in field populations of Mycosphaerella graminicola. Phytopathology 91:1011-1017.

63. Zhan, J., Pettway, R. E., and McDonald, B. A. 2003. The global genetic structure of the wheat pathogen Mycosphaerella graminicola is characterized by high nuclear diversity, low mitochondrial diversity, regular recombination, and gene flow. Fungal Genet. Biol. 38:286297.

64. Zhu, X. Q., Spratt, D. M., Beveridge, I., Haycock, P., and Gasser, R. B. 2000. Mitochondrial DNA polymorphism within and among species of Capillaria sensu lato from Australian marsupials and rodents. Int. J. Parasitol. 30:933-938. 